\title{
Assessment of the outcome of fracture intertrochanteric femur treated by trochanteric fixation nail in the elderly population
}

\author{
Vipin Tyagi ${ }^{1}$, Rahul Kakran', Amit Dwivedi' ${ }^{2 *}$, Fenil Shah ${ }^{2}$
}

\begin{abstract}
${ }^{1}$ Department of Orthopaedics, Yashoda Superspeciality Hospital, Nehrunagar, Ghaziabad, Uttar Pradesh, India
${ }^{2}$ Department of Orthopaedics, Santosh Medical College and Hospital, Ghaziabad, Uttar Pradesh, India
\end{abstract}

Received: 30 November 2020

Revised: 13 December 2020

Accepted: 18 December 2020

\author{
*Correspondence: \\ Dr. Amit Dwivedi, \\ E-mail: dramitdwivedi@yahoo.in
}

Copyright: (c) the author(s), publisher and licensee Medip Academy. This is an open-access article distributed under the terms of the Creative Commons Attribution Non-Commercial License, which permits unrestricted non-commercial use, distribution, and reproduction in any medium, provided the original work is properly cited.

\begin{abstract}
Background: Intertrochanteric fractures femur in elderly population are more commonly forbidden high morbidity. The surgical stabilization together with early rehabilitation is the main challenge. The elderly population have poor bone mass quality and also the chances of complications like nonunion or implant failure are more with conventional procedures. Stable fixation and early rehabilitation is the main aim in intertrochanteric fractures. The aim is to assess the functional outcome of intertrochanteric fractures femur managed by trochanteric fixation nail (TFN) in the elderly population.

Methods: The study includes 40 patients, 30 male and 10 female, with fracture intertrochanteric femur treated with TFN from September 2018 to May 2019 at Yashoda Superspeciality Hospital, Nehrunagar, Ghaziabad. The patients were evaluated at 4, 8, 12 weeks postoperatively and assessed by the Modified Harris hip score. Classification used is AO classification.

Results: The mean age of patients was 64 years. The mean duration of surgery was $48 \pm 10$ min. The Harris hip score was $96.90 \pm 4.60$, which is better than scores from other implants used for intertrochanteric fractures femur.

Conclusions: In this study, we conclude that TFN is a good choice in managing the intertrochanteric fractures, having higher bone union rate and less union time. The period of immobilization is decreased, early weight bearing and less complications.
\end{abstract}

Keywords: Intertrochanteric fracture, TFN, Trochanteric fixation nailing

\section{INTRODUCTION}

Intertrochanteric fractures are commonly encountered by the orthopaedic surgeons especially in the elderly population with osteoporotic bones. ${ }^{1,2}$ The mechanism of trauma is mainly due to fall, road traffic accident. ${ }^{3}$ Due to high complications with the conservative management such as joint stiffness, shortening, prolong immobilization, varus deformity, surgical management is preferred. ${ }^{4}$ Many varieties of implants can be used in this fractures, such as plates and screws, proximal femoral nail (PFN), and trochanteric fixation nailing (TFN). Rotational stability of the proximal femoral segment was improved after the development of $\mathrm{TFN}^{5}$ Also the intraoperative complications were reduced and early mobilization was achieved. In TFN, the principle is the sliding screw in the head and neck of femur which is attached to the intramedullary nail. This helps in proper anatomical reduction, blood supply is preserved, stable fixation is achieved and immobilization time is reduced.

\section{Aims and objective}

The aim is to assess the functional outcome of intertrochanteric fractures femur managed by $\mathrm{TFN}$ in the elderly population. 


\section{METHODS}

\section{Study design}

A retrospective study of intertrochanteric fracture femur that were managed with TFN. The sample size was taken as per the availability of the patients and according to the operating surgeon's choice.

\section{Place of study}

The study was conducted at Yashoda Superspeciality Hospital, Nehrunagar, Ghaziabad.

\section{Time of study}

The duration of the study was from September 2018 to May 2019.

\section{Inclusion criteria}

The study included patients with age $>50$ years, closed fractures, isolated intertrochanteric fracture of isolated limb and patients without co-morbidities.

\section{Exclusion criteria}

The study excluded patients with age <50 years, open fractures, patients with co-morbidities, polytrauma patients, pathological fracture and old neglected fracture more than 3 weeks old.

Preoperative planning was done along with X-rays. After giving aneasthesia, closed reduction done. Fracture fixation with TFN done by lateral approach. Guidewire and reaming were used in all operations. Post-operative follow up was done at 4,8 and 12 weeks.

Table 1: Number of patients classified according to the fracture pattern (AO classification).

\begin{tabular}{|lll|}
\hline SI no. & Type of fracture & Number \\
\hline $\mathbf{1}$ & A1.2 & 05 \\
\hline $\mathbf{2}$ & A1.3 & 08 \\
\hline $\mathbf{3}$ & A2.1 & 12 \\
\hline $\mathbf{4}$ & A2.2 & 08 \\
\hline $\mathbf{5}$ & A2.3 & 07 \\
\hline
\end{tabular}

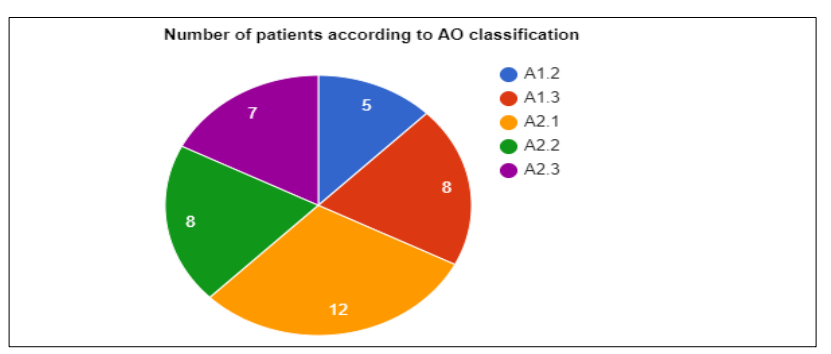

Figure 1: Number of patients classified according to AO classification.

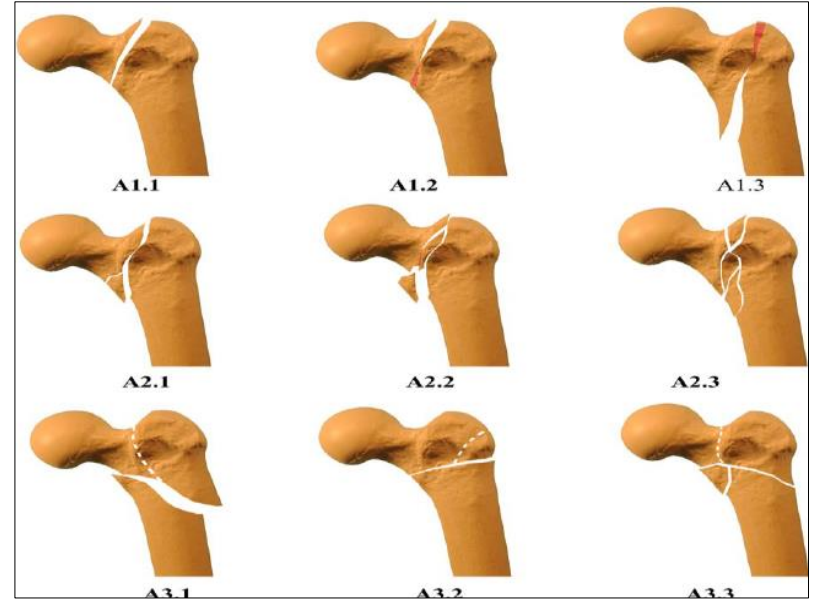

Figure 2: AO classification for intertrochanteric fracture femur.

Table 2: No. of patients according to the modified Harris hip score (results of performance of the postoperative patients as per MHHS).

\begin{tabular}{|lll|}
\hline $\begin{array}{l}\text { Modified Harris hip } \\
\text { score }\end{array}$ & $\begin{array}{l}\text { No. of } \\
\text { patients }\end{array}$ & Percentage \\
\hline Excellent & 20 & 50 \\
\hline Good & 16 & 40 \\
\hline Fair & 3 & 7.5 \\
\hline Poor & 1 & 2.50 \\
\hline Failed & 0 & 0 \\
\hline Total & 40 & 100 \\
\hline
\end{tabular}

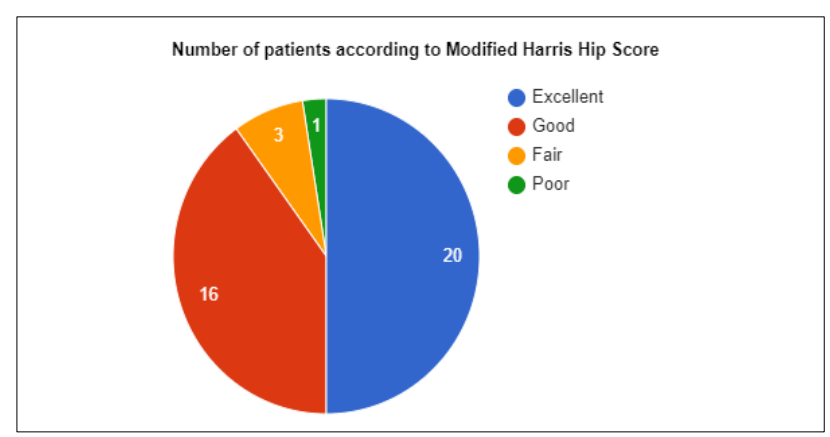

Figure 3: Number of patients classified according to modified Harris hip score.

\section{RESULTS}

Out of the 40 patients, 30 male (75\%) and 10 female (25\%), the youngest patient was 53 years and the oldest patient was 86 years. The mechanism of injury in 14 patients was due to fall and 26 patients had road traffic accident.

The callus formation was observed radiologically at the fracture site, the mean union time was $1.40 \pm 0.60$ months. 1 patient developed deep vein thrombosis. The mean modified Harris hip score was $96.90 \pm 4.60$. 


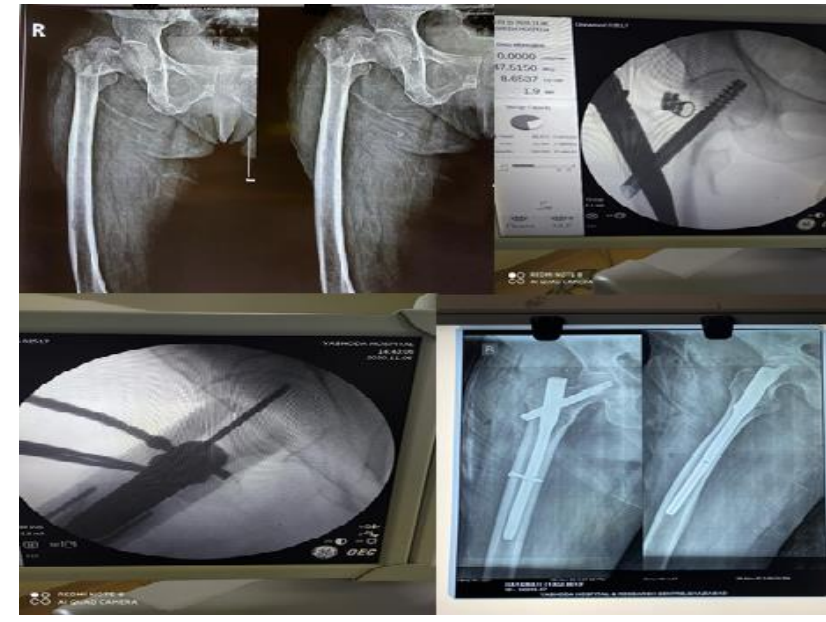

Figure 4: Pre-operative, intra-operative and postoperative $\mathrm{x}$-rays of a female 86 year old patient with intertrochanteric fracture femur managed with TFN.

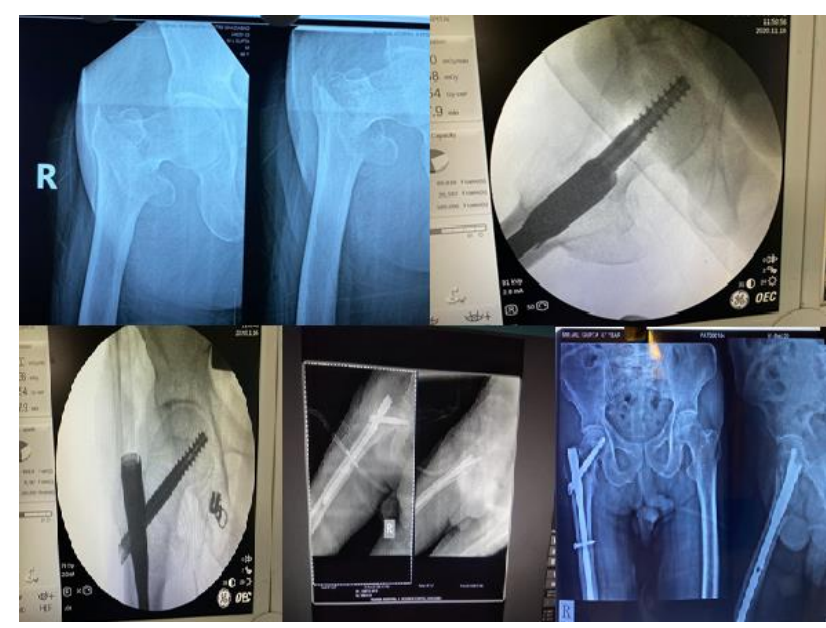

Figure 5: Pre-operative, intra-operative and postoperative $x$-rays of a 86 year old male patient with intertrochanteric fracture managed with trochanteric femoral nailing.

\section{DISCUSSION}

The intertrochanteric fracture is a tremendous burden regarding morbidity to the public health problem. Male are more commonly involved with such fractures than female. While managing the intertrochanteric fractures, various types of fixation devices like DHS, plating with screws, PFN, and TFN could be used. ${ }^{6-8}$

The main aim while operating the intertrochanteric fracture is the proper reduction of the fracture site and proper positioning of the nail along with the screws. ${ }^{9-11}$ Properly reduced fracture along with the fixation device have less chances of implant failure. TFN has short lever arm which reduces the bending stress and thus the chances of implant failure are reduced. Also the nail fixes in the medullary cavity, thus preventing medialization of the shaft of femur and excessive sliding. TFN can be used in all types of fracture pattern including subtrochanteric extension and reverse oblique fractures. ${ }^{12}$ The average operating time with TFN is less compared to the other fixation devices. The blood loss during the surgery and intra-operative complications are also less when compared to the other implants. The average healing time with TFN is less than that with DHS or plating. Also the rehabilitation is early with TFN compared to other fixation devices. After the patients were managed with trochanteric femoral nailing, the partial weight bearing was allowed by the second week in 80 percent of the patients. Full weight bearing was allowed by the sixth week. All the patients were assessed by the range of motion. Flexion, extension, internal rotation, abduction and external rotation was good to excellent in most of the patients managed with TFN. The fair to poor range of motion were due to poor compliance for the regular physiotherapy by the patients. The limitation of this study is the selection bias we introduced while the selection of the patients.

\section{CONCLUSION}

In this study, we conclude that TFN is a good choice in managing the intertrochanteric fractures provided proper patient selection, surgical method and proper instruments are used, and having higher bone union rate and less union time. The period of immobilization is decreased, early weight bearing and less complications makes TFN more preferable for intertrochanteric fracture fixation.

Funding: No funding sources

Conflict of interest: None declared

Ethical approval: The study was approved by the institutional ethics committee

\section{REFERENCES}

1. Dimon JH, Hughston JC. Unstable intertrochanteric fractures of the hip. J Bone Joint Surg Am. 1967;49:440-50.

2. Knobe M, Gradl G, Ladenburger A, Tarkin IS, Pape HC. Unstable intertrochanteric femur fractures: Is there a consensus on definition and treatment in Germany? Clin Orthop Relat Res. 2013;471:283140.

3. Dhanwal DK, Dennison EM, Harvey NC, Cooper C. Epidemiology of hip fracture: Worldwide geographic variation. Indian J Orthop. 2011;45:15-22.

4. Bannister GC, Gibson AG, Ackroyd CE, Newman $\mathrm{JH}$. The fixation and prognosis of trochanteric fractures: a randomized prospective controlled trial Clin Orthop. 1990;254:242-6.

5. Kyle RF, Cabanela ME, Russell TA, Swiontkowski MF, Winquist RA, Zuckerman JD, et al. Fractures of the proximal part of the femur. Instr Course Lect. 1995;44:227-53.

6. Adams CI, Robinson CM, Court-Brown CM, McQueen MM. Prospective randomized controlled trial of an intramedullary nail versus dynamic screw 
and plate for intertrochanteric fractures of the femur. J Orthop Trauma. 2001;15:394-400.

7. Gill JB, Jensen L, Chin PC, Rafiei P, Reddy K, Schutt RC Jr. Intertrochanteric hip fractures treated with the trochanteric fixation nail and sliding hip screw. J Surg Orthop Adv. 2007;16:62-6.

8. Nargesh A, Tiwari A, Muhammad S, Mehra A. Comparative study of the management of intertrochanteric fractures in the elderly: Short proximal femoral nail vs. dynamic hip screw. Sri Lanka J Surg. 2012;30:13-7.

9. Patil P, Shah J, Gunaki R, Lokare N, Gor R, Koli V, et al. A study of unstable intertrochanteric fractures treated with trochanteric fixation nail. Int J Curr Res. 2006;8:30742-8.

10. Domingo LJ, Cecilia D, Herrera A, Resines C. Trochanteric fractures treated with a proximal femoral nail. Int Orthop. 2001;25(5):298-301.
11. Bhandari S. Proximal femoral nail for unstable peritrochanteric fractures a panacea? J Maharashtra Orthop Assoc. 2005;2:69-72.

12. Brammar TJ, Kendrew J, Khan RJ, Parker MJ. Reverse obliquity and transverse fractures of the trochanteric region of the femur; a review of 101 cases. Injury. 2005;36:851-7.

Cite this article as: Tyagi V, Kakran R, Dwivedi A, Shah F. Assessment of the outcome of fracture intertrochanteric femur treated by trochanteric fixation nail in the elderly population. Int J Res Orthop 2020;7:125-8. 